\title{
Functional variables associated with the clinical grade of dyspnoea in coal miners with pneumoconiosis and mild bronchial obstruction
}

T T Bauer, G Schultze-Werninghaus, J Kollmeier, A Weber, R Eibel, B Lemke, E-W Schmidt

\begin{abstract}
Objectives-Dyspnoea is a common symptom in coal miners with pneumoconiosis. Among others, gas exchange disturbances due to airway obstruction or mismatch between ventilation and perfusion may be underlying mechanisms. The validation of dyspnoea by the degree of airway obstruction is controversial, because the extent of airway obstruction often does not correlate with the clinical grade of breathlessness.

Methods-The association was investigated between breathlessness (self reported, on a six point scale) and indices of submaximal spiroergometry in $66 \mathrm{coal}$ workers with radiographically confirmed pneumoconiosis (International Labour Organisation (ILO) grade of profusion $\geqslant 1 / 0$, mean (SD) age $64(5.5)$ years, mean (SD) forced expired volume in 1 second $\left(\mathrm{FEV}_{1}\right) 77.5$ (22.9) \% predicted).
\end{abstract}

Results-The clinical degree of breathlessness was independently associated with minute ventilation/oxygen consumption $\left(\dot{\mathrm{V} E} / \dot{\mathrm{V}} \mathrm{O}_{2}\right)$ ratio $(\boldsymbol{\beta} 0.423,95 \%$ confidence interval (95\% CI) 0.18 to 0.67 , $\mathrm{p}=0.001)$ and smoking $(\beta \quad 0.318,95 \% \mathrm{CI}$ 0.21 to $1.79, p=0.014$ ) in a multiple linear regression analysis. The $\dot{\mathrm{V} E} / \dot{\mathrm{V}} \mathrm{O}_{2}$ ratio $(\beta$ $0.556,95 \%$ CI 0.20 to $0.90, p=0.003$ ) was also the best predictor of breathlessness when only coal miners with airway obstruction $\left(\mathrm{FEV}_{1}<80 \%\right.$ predicted) were analyzed.

Conclusion-The $\dot{\mathrm{VE}} / \mathrm{V}^{\mathrm{V}} \mathrm{O}_{2}$ ratio as a measurement of mismatch between ventilation and perfusion predicted the clinical grade of breathlessness better than measurements of bronchial obstruction at rest in coal workers with pneumoconiosis.

(Occup Environ Med 2001;58:794-799)

Keywords: coal workers' pneumoconiosis; bronchial obstruction; ventilation

Pneumoconiosis is still a major cause of disability world wide despite a decreasing incidence in western countries. ${ }^{1}$ Underground coal workers are exposed to dust consisting of coal particles and free silica eventually resulting in coal workers pneumoconiosis. ${ }^{23}$ The disease is characterised by ventilation defects and dyspnoea. The verification and measurement of

\section{Main messages}

- The $\dot{\mathrm{VE}} / \mathrm{V}_{2}$ ratio during exercise is associated with the self reported degree of breathlessness in coal workers with pneumoconiosis.

- A higher $\dot{\mathrm{V} E} / \mathrm{V}_{2}$ ratio is found in patients with more exertional dyspnoea.

- Self reported dyspnoea is better described by the $\dot{\mathrm{VE}} / \mathrm{V}_{2}$ ratio during submaximal exercise testing with a steady state protocol than by the $\mathrm{FEV}_{1}$.

- A higher $\dot{\mathrm{VE}} / \dot{\mathrm{VO}}_{2}$ ratio was not found among smokers although they reported higher levels of dyspnoea than nonsmokers.

- The $\dot{\mathrm{VE}} / \dot{\mathrm{VO}}_{2}$ ratio may therefore be an interesting variable possibly to assess respiratory disability independent from smoking.

Policy implications

- Exercise testing should be included in the evaluation of respiratory disability in coal miners with pneumoconiosis.

- The $\dot{\mathrm{VE}} / \mathrm{VO}_{2}$ ratio should be assessed during a submaximal steady state protocol-for example, $50 \mathrm{~W}$.

- Mismatch between ventilation and perfusion should be considered in coal miners with mild bronchial obstruction and unexpectedly high self reported dyspnoea.

breathlessness is a cornerstone for the identification of clinically important occupational lung damage.

However, the correlation of functional variables obtained at rest-for example, forced expired volume in 1 second $\left(\mathrm{FEV}_{1}\right)$-with the clinical grade of dyspnoea is generally poor. ${ }^{4-6}$ Various approaches have been made to improve the prediction of exertional dyspnoea from pulmonary function tests and to provide an independent measure of dyspnoea. Cotes et al identified a reduced diffusing capacity and forced vital capacity (FVC) as predictors, ${ }^{7}$ but also hypothesised that measurements of ventilation standardised for oxygen uptake during submaximal exercise may improve the predictive power. ${ }^{6}$

The objective of this study was therefore to describe the association between the degree of 
breathlessness and functional indices of submaximal spiroergometry or pulmonary function tests in coal miners with pneumoconiosis

\section{Methods}

Coal miners were selected from a cohort investigated for compensation benefits in our institute between 1 December 1994 and 30 June 1997. All coal miners received compensation benefits at that time and data were obtained during a scheduled follow up visit. All patients with symptoms of chronic bronchitis and radiologically confirmed pneumoconiosis were asked to participate in this study.

Chronic bronchitis was defined as the presence of chronic productive cough for 3 months in each of 2 successive years. ${ }^{8}$

Chronic bronchitis with airflow obstruction was assumed in the presence of a $\mathrm{FEV}_{1} \leqslant 80 \%$ of the predicted value.

Radiologically confirmed pneumoconiosis was defined as profusion for small opacities of at least $1 / 0$ with or without large opacities (A, $\mathrm{B}$ ) according to the guidelines of the International Labour Organisation, Geneva. ${ }^{9}$

Exclusion criteria were the following: (a) denied informed consent, $(b)$ clinically apparent or history of congestive heart failure, ventricular arrhythmia, or severe arterial hypertension (systolic pressure at rest $\geqslant 180 \mathrm{~mm} \mathrm{Hg}$ or diastolic pressure $\geqslant 110 \mathrm{~mm} \mathrm{Hg}$ ), (c) severe physical or mental disability, (d) airflow obstruction stage II or worse $\left(\mathrm{FEV}_{1} \leqslant 50 \%\right.$ predicted), ${ }^{10}$ (e) large opacities (International Labour Organisation (ILO) classification C) on the chest radiograph, and $(f)$ oral corticosteroid medication during the preceding 4 weeks.

Chronic medication allowed during the study included theophylline, inhaled $\beta-2-$ adrenergic drugs, and inhaled corticosteroids. Written informed consent was obtained from all subjects. The study was approved by the ethics committee of the Ruhr-University, Bochum.

QUESTIONNAIRE

Respiratory symptoms were assessed by a questionnaire adapted from the British Medical Research Council (BMRC) questionnaire on respiratory symptoms and smoking habits. ${ }^{11}$ Smoking habits were grouped as non-smokers and smokers (ex-smokers and current smokers) and a full occupational history was obtained. In the questionnaire the frequency of cough $(0=$ none, $1=$ infrequent $(<3$ weeks/year in the preceding 2 consecutive years), $2=$ frequent (daily), $3=$ frequent cough attacks, and $4=$ frequent cough with dyspnoea or dyspnoea attacks) and phlegm $(0=$ none, $1=$ infrequent ( $<3$ weeks/year in the preceding 2 consecutive years), $2=$ frequent (daily), and $3=$ frequent with dyspnoea attacks) was obtained. Exertional dyspnoea was graded by a set of six questions about different levels of dyspnoea during walking on slight hills, level ground, or rest, ${ }^{11} 0=$ no dyspnoea, $1=$ dyspnoea during fast walking on level ground, walking up hill, or climbing stairs, $2=$ dyspnoea during regularly paced walking on flat ground, $3=$ dyspnoea during slow walking on flat ground requiring occasional stops, $4=$ dyspnoea during rest or during dressing, and 5=dyspnoea level 0-4 with occasional attacks of breathlessness.

\section{CHEST RADIOGRAPHY}

Routine posterior-anterior chest radiographs were obtained and evaluated separately by two expert radiologists according to the 1980 ILO classification. $^{9}$ The profusion score was converted to numerical numbers from 0 to 9 according to increasing density of small opacities $(0 / 0=0,0 / 1=1,1 / 0=2$, etc). Numbers assigned by each rater were compared by an independent third person and the mean was used when the scores differed by one step ( $5 v$ $6 ; 2 / 1 v 2 / 2$ resulted in a score of 5.5). The radiographs were reassessed by both raters under the same conditions in cases of discordance $\geqslant$ two steps $(5 \vee 7 ; 2 / 1 \vee 2 / 3$ ). If discordance persisted, a third radiologist was consulted and an agreement was reached among the three of them.

\section{PULMONARY FUNCTION}

Spirometry and body plethysmography were performed with a Jaeger IV device (Jaeger IV, Würzburg, Germany). For spirometry the trial with the highest $\mathrm{FEV}_{1}$ was selected and data were compared with reference values. ${ }^{12}$ The variables assessed were: resistance $\left(R_{t}\right)$, intrathoracic gas volume (ITGV), residual volume as a \% of total lung capacity (RV\% TLC), $\mathrm{FEV}_{1}$, and forced and inspiratory vital capacity (FVC, IVC). Diffusing capacity for $\mathrm{CO}\left(\mathrm{T}_{\mathrm{L}} \mathrm{CO}\right)$ was measured by a single breath method (Pneumotest Alveotest, Jaeger, Würzburg, Germany) and compared with reference values. ${ }^{13}$ Arterial capillary blood was drawn from the hyperaemic ear lobe with a heparinised capillary at rest and during steady state exercise (after 4 minutes). Hyperaemia was induced by a rubefacient (nicoboxil/nonivamid, Finalgon) and ensured visually. This method may underestimate arterial $\mathrm{CO}_{2}$ tension $\left(\mathrm{PaCO}_{2}\right)$, but arterial catheterisation was not permitted for ethical reasons. Samples were immediately analysed in a blood gas analyser (AVL 995-S automatic blood gas system, AVL Graz, Austria), that performed calibration cycles every 2 hours.

EXERCISE TESTING

Spiroergometry was performed on an electromagnetically braked bicycle in 30 degrees upright body position. The gas exchange was measured breath by breath (MedGraphics, CPX/D, Minneapolis, USA). Subjects breathed through a mouthpiece with a dead space volume of $20 \mathrm{ml}$ with a nose clip in place. Daily maintenance of the system included gas analyser calibration with a precision gas mixture and volume calibration with a 3 litre syringe before each exercise test. Heart rate was calculated by R-R intervals with the highest signal amplitude of a 12 lead configuration. Arterial blood pressure was measured by a sphygmomanometer at rest and during exercise. All exercise tests were performed between 0900 and 1200 and the exercise protocol 
Table 1 Demographic and clinical characteristics of coal miners eligible for the study and those included during the study period (Student's t test for continuous variables and $\chi^{2}$ test for frequencies, exact $p$ values are given)

\begin{tabular}{llll}
\hline & $\begin{array}{l}\text { Coal miners } \\
\text { included }(n=66)\end{array}$ & $\begin{array}{l}\text { Coal miners not } \\
\text { included }(n=94)\end{array}$ & p Value \\
\hline Age (y, mean (SD)) & $64(5.5)$ & $66(6.9)$ & $<0.001$ \\
BMI (kg/m², mean (SD)) & $26.1(2.7)$ & $26.1(3.7)$ & 0.063 \\
FEV (\% predicted, mean (SD)) & $77.5(22.9)$ & $75.2(26.4)$ & 0.429 \\
Duration of work underground (y, & $25.8(9.2)$ & $26.0(9.2)$ & 0.720 \\
$\quad$ mean (SD)) & & & \\
Smoking (n (\%)) & $8 / 66(12)$ & $15 / 94(16)$ & $0.495^{\star}$ \\
$\quad$ Non-smokers & $58 / 66(88)$ & $79 / 94(84)$ & \\
$\quad$ Smokers & & & \\
\hline
\end{tabular}

${ }^{\star} \mathrm{p}$ Value calculated with $\chi^{2}$ test.

included 2 minutes of rest, 2 minutes of unloaded pedalling, 6 minutes of loaded exercise ( $50 \mathrm{~W}$, pedalling speed $45-55 \mathrm{rpm}$ ), and recovery until baseline conditions were reached again. All indices were assessed in the steady state condition. Steady state was assumed if the slope fitted to data of the last 2 minutes of exercise (minute 4-6 of loaded exercise) was $\leqslant 0.1 \mathrm{ml} / \mathrm{min} / \mathrm{kg}$ body weight for oxygen uptake or $\leqslant 10 \mathrm{ml} / \mathrm{min}$ for $\mathrm{CO}_{2}$ output. The data obtained during exercise were printed as a standard eight breath averaged plot after the test had been completed. Slopes were eye fitted to data of the last 2 minutes of the exercise test and the values were read from the abscissa of the same plot. The variables obtained for analysis were heart rate (HR), minute ventilation $(\dot{\mathrm{VE}})$, oxygen uptake $\left(\dot{\mathrm{VO}}_{2}\right)$, carbon dioxide output $\left(\mathrm{VCO}_{2}\right)$, ventilatory equivalent for $\mathrm{O}_{2}\left(\dot{\mathrm{V} E} / \dot{\mathrm{V}} \mathrm{O}_{2}\right.$ ratio) and $\mathrm{CO}_{2}(\dot{\mathrm{VE}} /$ $\dot{\mathrm{V} C O}{ }_{2}$ ratio), end expiratory $\mathrm{O}_{2}\left(\mathrm{P}_{\mathrm{ET}} \mathrm{O}_{2}\right)$, end expiratory $\mathrm{CO}_{2}\left(\mathrm{P}_{\mathrm{ET}} \mathrm{CO}_{2}\right)$, respiratory exchange ratio $\left(\mathrm{V}^{2} \mathrm{CO}_{2} / \mathrm{VO}_{2}\right)$, dead space/tidal volume ratio $\left(\mathrm{VD} / \mathrm{VT}=\left(\mathrm{PaCO}_{2}-\mathrm{P}_{\mathrm{E}} \mathrm{CO}_{2}\right) /\right.$ $\left.\mathrm{PaCO}_{2}\right)-0.021 / \mathrm{VT}$ ), alveolar-arterial $\mathrm{PO}_{2}$ difference, $\mathrm{P}(\mathrm{A}-\mathrm{a}) \mathrm{O}_{2}$, and arterial end tidal $\mathrm{PCO}_{2}$ difference, $\mathrm{P}(\mathrm{a}-\mathrm{ET}) \mathrm{CO}_{2}$.

STATISTICAL ANALYSIS

The sample size was estimated according to results of a pilot study including 20 patients with pneumoconiosis and 24 healthy control subjects. ${ }^{14}$ We found highly significant differences between patients for the $\dot{\mathrm{VE}} / \dot{\mathrm{V}} \mathrm{O}_{2}$ ratio and aimed at a larger sample size for our consecutive patients because no control subjects were included in the present study. Based on data of the preceding 2 years, we estimated that a total of 140 patients would be transferred to the hospital for respiratory disability assessment during the study period. We calculated a denial rate of $50 \%$ for informed consent or patients fulfilling exclusion criteria. Of the remaining estimated 70 patients we calculated an overall $20 \%$ drop out rate (including technical problems) during the exercise test $(n=56$ remaining). No subjects of the first study ${ }^{14}$ were included in the actual trial.

Data are reported as frequencies or means (SD) for continuous and as median (interquartile range $(I Q R))$ for ordinal variables. Frequencies were compared by $\chi^{2}$ test or Fisher's exact test where appropriate. Means were compared by unpaired Student's $t$ test and results of blood gas analysis before and during exercise were compared by paired Student's $t$ test.

For describing the degree of dyspnoea by functional variables, a multiple linear regression analysis was used. The variable was tested for normal distribution by KolmogorovSmirnov test before the procedure to test for normal distribution. A stepwise forward model was used to give transparency of variable selection and to reduce the risk of overfitting the data. ${ }^{15}$ The following variables were investigated in connection with the clinical grade of breathlessness: age, smoking history, $\mathrm{FEV}_{1}$, $\mathrm{FEV}_{1} / \mathrm{FVC}, \mathrm{T}_{\mathrm{L}} \mathrm{CO}, \dot{\mathrm{VE}} / \dot{\mathrm{V}}_{2}$ ratio, and arterial end tidal $\mathrm{PCO}_{2}$ difference, $\mathrm{P}(\mathrm{a}-\mathrm{ET}) \mathrm{CO}_{2}$ (positive or negative). The $\dot{\mathrm{VE}} / \mathrm{V} \mathrm{CO}_{2}$ ratio was not included in the multivariate analysis because of its close physiological and mathematical correlation to the $\dot{\mathrm{VE}} / \mathrm{VOO}_{2}$ ratio. ${ }^{16}$ Results of this analysis are reported as the standardised $\beta$ coefficient, the $95 \%$ confidence interval $(95 \%$ $\mathrm{CI}$ ), and the level of significance. The standardised $\beta$ coefficient is the regression coefficient for change in the dependent variable per unit change in the predictor variable. This allows the direct comparison of the effect in a multivariable model.

All data were processed with SPSS version 8.01 on a Windows 98 operating system. Comparisons were regarded as significant with $\mathrm{p}<0.05$ (all two tailed). Exact levels of significance are reported.

\section{Results}

DESCRIPTION OF THE POPULATION

A total of 160 coal miners were investigated and $66 / 160$ were included in this study $(41 \%)$. Seventy three coal miners denied informed consent for this extended investigation (73/ $160,46 \%)$ and 21 had at least one exclusion criterion (21/160,13\%). Table 1 compares the clinical characteristics of coal miners eligible for the study and those included. Coal miners included were on average 2 years younger than those not included $(\mathrm{p}<0.001)$. No other significant differences were found for this comparison. A total of 58/66 (88\%) coal miners were smokers or ex-smokers and the median values according to the grading obtained by the questionnaire for dyspnoea, frequency of cough, and phlegm were 2 IQR 1, 1 IQR 2, and 1 IQR 2, respectively.

Coal miners included in the study had the following radiographic scores according to ILO classification 1980: $1 / 0(5 / 66,8 \%), 1 / 1(16 / 66$, $24 \%), 1 / 2$ (9/66, 14\%), $2 / 1(17 / 66,26 \%), 2 / 2$ (13/66, 20\%), 2/3 (3/66, 5\%), 3/2 (3/66, 5\%), p/p $(9 / 66,13 \%), p / q(26 / 66,39 \%), q / p(3 / 66$, $5 \%), q / q(14 / 66,21 \%), q / r(11 / 66,17 \%), r / q$ $(1 / 66,2 \%), r / r(2 / 66,3 \%)$. The frequency of large opacities was $15 / 66$ for ILO classification A $(23 \%)$ and $23 / 66$ for ILO classification B (35\%). Radiographic signs of emphysema were present in 30/66 (46\%) radiographs.

Results of the pulmonary function tests, blood gas analyses, and spiroergometry are summarised in table 2. Overall 12/66 (18\%) exercise tests could not be included in this study for the following reasons: early ending of 
Table 2 Functional indices of pulmonary function test, blood gas analyses, and spiroergometry during a constant $50 \mathrm{~W}$ workload

\begin{tabular}{|c|c|}
\hline & Mean (SD) \\
\hline \multicolumn{2}{|l|}{ Lung function test: } \\
\hline $\mathrm{FEV}_{1}(\%$ predicted $)$ & $77.5(22.9)$ \\
\hline $\mathrm{FEV}_{1} / \mathrm{FVC}$ (\% predicted) & $85.2(16.2)$ \\
\hline TLC (\% predicted) & $95.4(11.1)$ \\
\hline $\mathrm{R}_{\mathrm{t}}\left(\mathrm{hPa} \times \mathrm{l}^{-1} \times \mathrm{s}\right)$ & $3.2(1.5)$ \\
\hline ITGV (\% predicted) & $112.1(24.6)$ \\
\hline RV\%TLC (\% predicted) & $119.8(25.2)$ \\
\hline IVC (\% predicted) & $89.5(14.4)$ \\
\hline $\mathrm{T}_{\mathrm{L}} \mathrm{CO}(\%$ predicted $)$ & $80.5(4.7)$ \\
\hline \multicolumn{2}{|l|}{ Blood gas analyses: } \\
\hline $\mathrm{PaO}_{2}$, rest $(\mathrm{mm} \mathrm{Hg})$ & $76.6(10.9)$ \\
\hline $\mathrm{PaO}_{2}$, exercise $(\mathrm{mm} \mathrm{Hg})$ & $77.9(11.1)$ \\
\hline $\mathrm{PaCO}_{2}$, rest $(\mathrm{mm} \mathrm{Hg})$ & $37.9(2.9)$ \\
\hline $\mathrm{PaCO}_{2}$, exercise $(\mathrm{mm} \mathrm{Hg})$ & $37.8(4.0)$ \\
\hline \multicolumn{2}{|l|}{ Spiroergometry:^ } \\
\hline $\mathrm{HR}(\mathrm{bpm})$ & $101.8(12.4)$ \\
\hline VE $(1 / \mathrm{min})$ & $31.7(4.7)$ \\
\hline$\dot{\mathrm{V}} \mathrm{O}_{2}(\mathrm{ml} / \mathrm{kg} / \mathrm{kg}$ body weight $)$ & $11.9(1.8)$ \\
\hline $\mathrm{P}_{\mathrm{ET}} \mathrm{O}_{2}(\mathrm{~mm} \mathrm{Hg})$ & $116.1(7.4)$ \\
\hline $\mathrm{P}_{\mathrm{ET}} \mathrm{CO}_{2}(\mathrm{~mm} \mathrm{Hg})$ & $36.7(4.9)$ \\
\hline Respiratory exchange ratio (RER) & $0.86(0.08)$ \\
\hline $\mathrm{P}(\mathrm{A}-\mathrm{a}) \mathrm{O}_{2}(\mathrm{~mm} \mathrm{Hg})$ & $26.7(11.2)$ \\
\hline $\mathrm{P}(\mathrm{a}-\mathrm{ET}) \mathrm{CO}_{2}(\mathrm{~mm} \mathrm{Hg})$ & $0.8(4.0)$ \\
\hline VD/VT (ratio) & $0.33(0.05)$ \\
\hline ṾE/ & $34.9(8.1)$ \\
\hline$\dot{\mathrm{VE}} / \mathrm{VCO}_{2}$ (ratio) & $39.9(7.1)$ \\
\hline
\end{tabular}

^Data from $12 / 66$ coal miners were not include in the analysis.

the exercise test by the patient due to general discomfort, leg or chest pain, or dryness of the mouth 6/12 (50\%), equipment failure $2 / 12$ $(17 \%)$, and failure to fulfill steady state criteria 5/12 (42\%). Neither $\mathrm{PaO}_{2}(\mathrm{p}=0.222)$ nor $\mathrm{PaCO}_{2}(\mathrm{p}=0.941)$ changed significantly from rest to exercise.

\section{ASSOCIATION OF THE DEGREE OF}

BREATHLESSNESS WITH FUNCTIONAL VARIABLES

The results of the multiple linear regression for the 54 coal miners who could be included in this analysis are shown in table 3. The degree of dyspnoea as assessed by the questionnaire was positively associated with $\dot{\mathrm{VE}} / \dot{\mathrm{VO}}_{2}(\beta 0.423$, $95 \%$ CI 0.18 to $0.67, \mathrm{p}=0.001)$. This indicates that a higher degree of breathlessness on the self reported scale is strongly associated with an increased $\dot{\mathrm{VE}} / \mathrm{VO}_{2}$ during constant $50 \mathrm{~W}$ exercise (fig 1). Also, a positive relation between smoking and the degree of breathlessness $(\beta$ $0.318,95 \%$ CI 0.21 to $1.71, \mathrm{p}=0.014$ ) could be established in this multivariable analysis. Smokers or ex-smokers reported higher dyspnoea scores than non-smokers (2 IQR $1 v 2$ IQR 1, $p=0.036$, fig 2). By contrast, the $\dot{\mathrm{VE}} / \mathrm{VO}_{2}$ ratio was not significantly different

Table 3 Results of the multiple linear regression analysis (final best fitting model) with the degree of breathlessness as the dependent variable

\begin{tabular}{|c|c|c|c|}
\hline & $\beta$ & $95 \% C I$ & $p$ Value \\
\hline \multicolumn{4}{|l|}{ Variables in the equation } \\
\hline$\dot{\mathrm{VE}} / \dot{\mathrm{V} O} \mathrm{O}_{2}$ (ratio) & 0.423 & 0.18 to 0.67 & 0.001 \\
\hline Smoking (non- versus ex- or current smokers) & 0.318 & $\begin{array}{l}0.21 \text { to } \\
\text { standardiz ed } \\
\text { regression } \\
\text { coefficient } \\
1.79\end{array}$ & 0.014 \\
\hline \multicolumn{4}{|l|}{ Variables not in the equation } \\
\hline Age (y) & 0.229 & - & 0.101 \\
\hline $\mathrm{D}_{\mathrm{L}, \mathrm{co}}(\%$ predicted $)$ & -0.098 & - & 0.479 \\
\hline $\mathrm{FEV}_{1}(\%$ predicted $)$ & -0.107 & - & 0.926 \\
\hline $\mathrm{FEV}_{1} / \mathrm{FVC}(\%$ predicted) & -0.021 & - & 0.704 \\
\hline $\mathrm{P}(\mathrm{a}-\mathrm{ET}) \mathrm{CO}_{2}(\mathrm{~mm} \mathrm{Hg})$ & -0.179 & - & 0.172 \\
\hline
\end{tabular}

$\beta=$ standardised regression coefficient.

$95 \%$ CIs could only be computed for variables included in the final model.

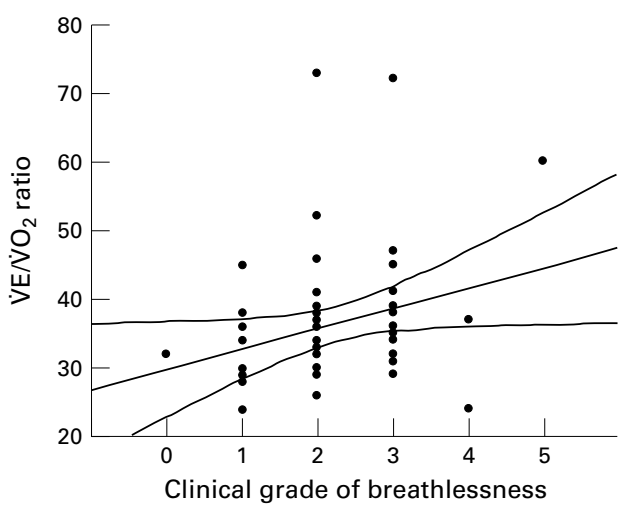

Figure 1 Regression of the $\dot{\mathrm{V}} / \dot{\mathrm{V}} \mathrm{O}_{2}$ ratio measured during submaximal steady state exercise on the clinical grade of breathlessness. Points indicate individual data. The regression line and $95 \%$ CIs are shown. The number of dots do not correspond exactly to the patients included in the analysis $(n=54)$ due to graphical overlap.

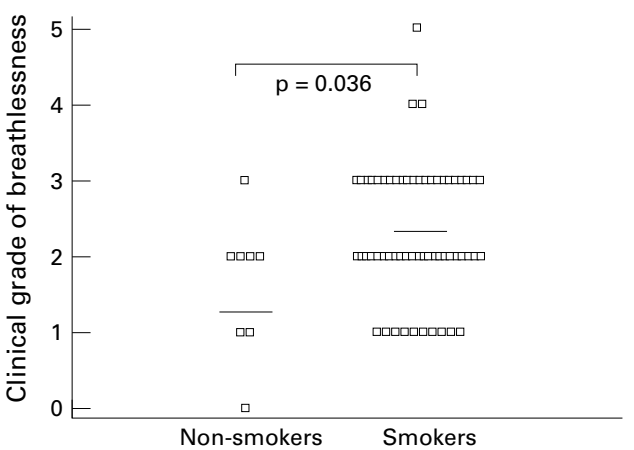

Figure 2 Comparison of the $\dot{V} E / \dot{V} \mathrm{O}_{2}$ ratio between non-smokers and smokers. Open squares indicate individual data and lines indicate means. Student's t test was used for comparison.

when smokers and ex-smokers (34.9 (7.8)) were compared with non-smokers (35.0 (11.9), $\mathrm{p}=0.979)$. However, the number of non-smokers was low in this cohort $(n=8)$ and formal interaction analysis to test for independency of effects was not undertaken.

SUBANALYSIS FOR COAL MINERS WITH AND WITHOUT AIRWAY OBSTRUCTION

Smoking had to be removed from the independent variable list when the multiple regression analysis was repeated for coal miners with and without airway obstruction, because all smokers had airway obstruction according to the definition. The degree of breathlessness was also positively associated with $\dot{\mathrm{VE}} / \mathrm{VO}_{2}$ ( $\beta 0.556,95 \%$ CI 0.20 to 0.90 , $\mathrm{p}=0.003)$ in the subgroup of coal miners with airway obstruction. The $\mathrm{T}_{\mathrm{L}} \mathrm{CO}(\beta-0.571,95 \%$ CI -0.95 to $-0.20, p=0.004$ ) was the single best predictor of the degree of breathlessness when coal miners without airway obstruction were studied exclusively.

\section{Discussion}

The main results of this study were: (1) The $\dot{\mathrm{VE}} / \dot{\mathrm{VO}}_{2}$ ratio during steady state exercise was associated with breathlessness in coal miners with pneumoconiosis, whereas $\mathrm{FEV}_{1}$ or $\mathrm{FEV}_{1}$ / FVC were not. (2) The association between breathlessness and the $\dot{\mathrm{VE}} / \dot{\mathrm{V}} \mathrm{O}_{2}$ ratio was strongest in coal miners with pneumoconiosis 
and airway obstruction $\left(\mathrm{FEV}_{1} \leqslant 80 \%\right.$ of predicted). (3) Smoking was associated with a higher degree of breathlessness but not with the $\dot{\mathrm{VE}} / \mathrm{VO}_{2}$ ratio during steady state exercise in the population studied.

Dyspnoea is a subjective sensation with a complex pathophysiological basis. Among the contributors that have been discussed are diaphragmatic fatigue, ${ }^{17}$ physiological signalling, ${ }^{18}$ and most commonly bronchial obstruction. Obstructive airway disease as measured by pulmonary function tests remains the basis for grading respiratory disability in patients with pneumoconiosis, although more complex methods have been proposed. ${ }^{19}$ However, measurements of pulmonary function tests are only poorly associated with the clinical degree of breathlessness. This has been verified for normal subjects, ${ }^{20}$ patients with COPD, ${ }^{21}$ silicosis, ${ }^{5}$ and coal workers' pneumoconiosis. ${ }^{4}$ Our results corroborate these negative findings because neither $\mathrm{FEV}_{1}$ nor $\mathrm{FEV}_{1} / \mathrm{FVC}$ were significantly associated with the dyspnoea score in multivariate analyses.

In our study, with a submaximal $50 \mathrm{~W}$ steady state protocol to minimise bias by the subject's effort, we found a strong association between the clinical grade of breathlessness and the $\dot{\mathrm{VE}} / \dot{\mathrm{V}} \mathrm{O}_{2}$ ratio during stable exercise. The $\dot{\mathrm{VE}} / \dot{\mathrm{VO}}_{2}$ ratio measures gas exchange efficiency and is also a measure of uneven ventilation/ perfusion $(\dot{\mathrm{V}} / \mathrm{Q}){ }^{22}$ The $\dot{\mathrm{VE}} / \mathrm{V}_{2}$ ratio is influenced by the anaerobic threshold and is highest at rest and decreases during exercise in healthy subjects until the anaerobic threshold is reached but remains increased in patients with uneven $\dot{\mathrm{V}} \mathrm{A} / \mathrm{Q} .{ }^{23}$ We did not include a maximal work rate test because we considered this to be of limited information in a compensation process due to the strong dependency on motivation for this variable. Therefore, we could not exactly define the exercise modality (aerobic or anaerobic) at the steady state level. However, we think that this is unimportant for our study because we consider it of limited value to differentiate between the aetiologies of dyspnoea at the $50 \mathrm{~W}$ level. Also, the end tidal $\mathrm{PCO}_{2}$ difference $\left(\mathrm{P}(\mathrm{a}-\mathrm{ET}) \mathrm{CO}_{2}\right)$ remained positive during exercise indicating decreased $\mathrm{CO}_{2}$ clearance from the alveoli, most likely due to uneven $\dot{\mathrm{V}} / \mathrm{Q} \cdot{ }^{24}$ Voluntary hyperventilation may also result in a high $\dot{\mathrm{VE}} / \mathrm{V} \mathrm{O}_{2}$ ratio during exercise but is accompanied by corresponding changes in $\mathrm{PaCO}_{2}{ }^{23}$ However, we did not find any decrease in capillary $\mathrm{PaCO}_{2}$ during exercise which may rule this possibility out confidently. We may therefore conclude that the clinical degree of breathlessness correlates better with measurements of uneven $\dot{V}_{A} / Q$ during exercise, than with measurements of airway obstruction at rest in coal workers with pneumoconiosis. However, future studies should make an attempt to confirm this finding by other measurements of uneven $\dot{\mathrm{V}}_{\mathrm{A}} / \mathrm{Q}$ such as the multiple inert gas elimination technique. ${ }^{25}$

The second important result of this study was that the $\dot{\mathrm{VE}} / \mathrm{VO}_{2}$ ratio remained the best predictor of self rated breathlessness even in coal workers with airway obstruction. In our study we used a submaximal exercise protocol with breathing patterns that resemble daily activities better than the forced manoeuvre necessary to measure $\mathrm{FEV}_{1}$. Airway obstruction also contributes to uneven $\dot{V}_{A} / Q^{25}$ and our finding may therefore indicate that it is probably the degree of $\dot{V}_{A} / Q$ mismatch that causes dyspnoea in this population rather than bronchial obstruction.

The $\mathrm{T}_{\mathrm{L}} \mathrm{CO}$ remained the best predictor of breathlessness in the multivariate analysis in the population with pneumoconiosis without airway obstruction thus corroborating previous findings. ${ }^{76}$ A decreased $\mathrm{T}_{\mathrm{L}} \mathrm{CO}$ correlates well with the functional impairment due to emphysema ${ }^{27}$ which was also a frequent finding in our population with pneumoconiosis. ${ }^{28-30}$

As expected, smoking was related to a higher degree of self reported breathlessness in our study. However, it is noteworthy that smoking and the $\dot{\mathrm{VE}} / \mathrm{V} \mathrm{O}_{2}$ ratio during exercise were independently associated with dyspnoea. Smoking also did not contribute to the level of the $\dot{\mathrm{VE}} / \mathrm{V}_{2}$ ratio when smokers and nonsmokers were compared. This indicates that measurements of the $\dot{\mathrm{V} E} / \dot{\mathrm{VO}}_{2}$ ratio may be helpful to differentiate between dyspnoea attributable to smoking or pneumoconiosis. However, these data have to be interpreted with caution because only a few coal miners were non-smokers in our study and therefore a formal interaction analysis could not be performed in our statistical model.

There are limitations to this study that deserve consideration. The participation rate in our study was $41 \%$ of the initially approached subjects. This was not unexpected because the study protocol required an exercise test which imposes an additional burden on the patients. As older and sicker patients are more likely to decline the participation of this study our sample may have been selected in that way. However, special care was taken to document this possible bias and at least the lack of a significant difference in $\mathrm{FEV}_{1}$ between the study group and the group of subjects declining participation indicated that this bias may have been minimal.

All coal miners were investigated during the compensation process and it might be argued that they tried to overestimate their exertional disability. This limitation, however, applies only to the average level of the dyspnoea score but not to associations found in this study. Up to date there are no objective measures of dyspnoea and all self rated scores are subject to this limitation in a study on coal miners.

In conclusion, we found that self rated breathlessness was approximated best by the $\dot{\mathrm{VE}} / \dot{\mathrm{VO}}_{2}$ ratio measured during steady state submaximal exercise, even in coal miners with airway obstruction. These results suggest that measurement of uneven $\dot{\mathrm{V}} \mathrm{A} / \mathrm{Q}$ may be a better predictor of dyspnoea than measurements of airway obstruction in coal miners with mild to moderate pneumoconiosis. Smoking also contributed to a higher degree of breathlessness but did not affect the $\dot{\mathrm{VE}} / \mathrm{VO}_{2}$ levels. This may 
Table 4 Abbreviations used in alphabetical order

\begin{tabular}{|c|c|}
\hline BMRC & British Medical Research Council \\
\hline $\mathrm{CB}$ & Chronic bronchitis \\
\hline COPD & Chronic obstructive pulmonary disease \\
\hline $\mathrm{T}_{\mathrm{L}} \mathrm{CO}$ & Diffusing capacity for $\mathrm{CO}$ \\
\hline $\mathrm{FEV}_{1}$ & Forced expiratory flow in 1 second \\
\hline FVC & Forced vital capacity \\
\hline HR & Heart rate \\
\hline ILO & International Labour Office \\
\hline ITGV & Intrathoracic gas volume \\
\hline IVC & Inspiratory vital capacity \\
\hline $\mathrm{P}(\mathrm{A}-\mathrm{a}) \mathrm{O}_{2}$ & Alveolar-arterial $\mathrm{PaO}_{2}$ difference \\
\hline $\mathrm{P}(\mathrm{a}-\mathrm{ET}) \mathrm{CO}_{2}$ & Arterial end-tidal $\mathrm{PCO}_{2}$ difference \\
\hline $\mathrm{PaO}_{2}$ & Partial arterial pressure for $\mathrm{O}_{2}$ \\
\hline $\mathrm{PaCO}_{2}$ & Partial arterial pressure for $\mathrm{CO}_{2}$ \\
\hline$\%$ Predicted & Percent of predicted \\
\hline $\mathrm{P}_{\mathrm{ET}} \mathrm{CO}_{2}$ & End-expiratory $\mathrm{CO}_{2}$ \\
\hline $\mathrm{P}_{\mathrm{ET}} \mathrm{O}_{2}$ & End-expiratory $\mathrm{O}_{2}$ \\
\hline PFT & Pulmonary function test \\
\hline RER & Respiratory exchange ratio \\
\hline $\mathrm{R}_{\mathrm{t}}$ & Airway resistance \\
\hline RV\%TLC & Residual volume in \% total lung capacity \\
\hline TLC & Total lung capacity \\
\hline$\dot{\mathrm{VA}} / \mathrm{Q}$. & Ventilation or perfusion \\
\hline$\dot{\mathrm{V} C O}$ & $\mathrm{CO}_{2}$ output \\
\hline$\dot{\mathrm{VE}}$ & Minute ventilation \\
\hline$\dot{\mathrm{V}} \mathrm{E} / \mathrm{V}_{2}$ & Ventilatory equivalent for $\mathrm{O}_{2}$ \\
\hline$\dot{\mathrm{V}} \mathrm{E} / \dot{\mathrm{VCO}}_{2}$ & Ventilatory equivalent for $\mathrm{CO}_{2}$ \\
\hline $\mathrm{VO}_{2}$ & Oxygen uptake \\
\hline
\end{tabular}

indicate that the $\dot{\mathrm{V} E} / \dot{\mathrm{V}} \mathrm{O}_{2}$ ratio may bear discriminant potential for dyspnoea attributable to either smoking or pneumoconiosis.

The study was supported by the Bergbau Berufsgenossenschaft (BBG), Bochum/ Germany.

1 American Thoracic Society. Adverse effects of crystalline silica exposure. Am f Respir Crit Care Med 1997;155:761-8.

2 Fisher ER, Watkins G, Lam NV. Objective pathological diagnosis of coal workers' pneumoconiosis. FAMA 1981; 245:1829-34.

3 Cockcroft AE, Seal RME, Wagner JC. Postmortem study of emphysema in coalworkers and non-coalworkers. Lancet 1982;ii:600-3.

4 Cooper JK, Johnson TP. Exercise capacity in coal workers pneumoconiosis: an analysis using causal modeling. $\mathrm{Br} \mathcal{F}$

5 Violante B, Brusasco V, Buccheri G. Exercise testing in radiologically limited simple pulmonary silicosis. Chest 1986;90:411- 15

6 Cotes JE, Zejda J, King B. Lung function impairment as a guide to exercise limitation in work-related lung disorders. Am Rev Respir Dis 1988;137:1089-93.

7 Musk AW, Bevan C, Campbell MJ, et al. Factors contributing to the clinical grade of breathlessness in coalworkers with pneumoconiosis. Bull Eur Physiopathol Respir 1979;15: 343-53.

8 American Thoracic Society. Chronic bronchitis, asthma, pulmonary emphysema. A statement by the committee on diagnostic standards for non-tuberculous disease. Am Rev Respir Dis 1962;85:762-8.

9 International Labor Office. Guidelines for the use of ILO classification of radiographs of pneumoconiosis. Revised edition 1980. Geneva: International Labour Office, 1995. (OSH 1980. Geneva:
series (rev).)
10 American Thoracic Society. Lung function testing: Selection of reference values and interpretative strategies. $\mathrm{Am}$ tion of reference values and interpr
Rev Respir Dis 1991;144:1202-18.

11 Ferris BG. Epidemiology standardization project: Recommended respiratory disease questionnaires for use with adults and children in epidemiological research. Am Rev Respir Dis 1978;118:7-54.

12 Quanjer PH, Tammeling GJ, Cotes JE, et al. Lung volumes and forced ventilatory flows. Report of a working party. Standardization of lung function tests. European Community for steel and coal. Official statement of the European Respiratory Society. Eur Respir f 1993;6:5-40.

13 Cotes JE, Chinn DJ, Quanjer PJ, et al. Standardization of the measurement of transfer factor (diffusing capacity). Report of a working party. Standardization of lung function tests. European Community for steel and coal. Official statement of the European Respiratory Society. Eur Respir $\mathcal{f}$ 1993;6:41-52.

14 Duvenkamp I, Bauer TT, Schmidt EW, et al. Submaximal spiroergometric stress study in patients with mixed dust pneumoconiosis. Pneumologie 1998;52:188-9.

15 Concato J, Feinstein AR, Holford TR. The risk of determining risk with multivariable models. Ann Intern Med 1993;118:201-10.

16 Wasserman K, Hansen JE, Sue DY, et al. Measurements during integrative cardiopulmonary exercise testing. In: Wasserman K, Hansen JE, Sue DY, et al, eds. Principles of exercise testing and interpretation, 2nd ed. Philadelphia: Lea and Febiger, 1994:52-78.

17 Babcock MA, Johnson BD, Pegelow DF, et al. Hypoxic effects on exercise-induced diaphragmatic fatigue in normal healthy humans. F Appl Physiol 1995;78:82-92.

18 Harty HR, Corfield DR, Schwartzstein RM, et al. External thoracic restriction, respiratory sensation, and ventilation during exercise in men. F Appl Physiol 1999;86:1142-50.

19 Cotes JE, Chinn DJ, Reed JW, et al. Experience of a standardised method for assessing respiratory disability. Eur Respir 7 1994;7:875-80.

20 Pineda H, Haas F, Axen K, et al. Accuracy of pulmonary function tests in predicting exercise tolerance. Chest 1984; 86:564-7.

21 Wegner RE, Jorres RA, Kirsten DK, et al. Factor analysis of exercise capacity, dyspnea ratings and lung function in patients with severe COPD. Eur Respir f 1994; 7:725-9.

22 Wasserman K. Diagnosing cardiovascular and lung pathophysiology from exercise gas exchange. Chest 1997;112: 1091-101.

23 Wasserman K, Hansen JE, Sue DY, et al, eds. Principles of exercise testing and interpretation, 2 nd ed. Philadelphia: Lea and Febiger, 1994:86-90.

24 Wasserman K, Whipp BJ, Davis JA. Respiratory physiology of exercise: metabolism, gas exchange and ventilatory control. In: Widdicombe JG, ed. International review of physiology III. Baltimore: University Park Press, 1996:149-211.

25 Rodriguez-Roisin R, Roca J. Pulmonary gas exchange. In: Calverly P, Pride N, eds. Chronic obstructive pulmonary disease. London: Chapman and Hall, 1995:161-84.

26 Sue DY, Oren A, Hansen JE, et al. Diffusing capacity for carbon monoxide as a predictor of gas exchange during exercise. N Engl f Med 1987;316:1301-6.

27 Clausen JL. The diagnosis of emphysema, chronic bronchitis and asthma. Clin Chest Med 1990;11:405-16.

28 Hnizdo E, Sluis Cremer GK, Abramowitz JA. Emphysema type in relation to silica dust exposure in South African gold miners. Am Rev Respir Dis 1991;143:1241-7.

29 Hnizdo E, Sluis-Cremer GK, Baskind E, et al Emphysema and airway obstruction in non-smoking South African gold miners with long exposure to silica dust Occup Environ Med 1994;51:557-63.

30 Cowie RL, Hay M, Thomas RG. Association of silicosis, lung dysfunction, and emphysema in gold miners. Thorax 1993;48:746-9.

\section{Correspondence and editorials}

Occupational and Environmental Medicine welcomes correspondence relating to any of the material appearing in the journal. Results from preliminary or small scale studies may also be published in the correspondence column if this seems appropriate. Letters should be not more than 500 words in length and contain a minimum of references. Tables and figures should be kept to an absolute minimum. Letters are accepted on the understanding that they be subject to editorial revision and shortening.

The journal also publishes editorials which are normally specially commissioned. The Editor welcomes suggestions regarding suitable topics; those wishing to submit an editorial, however, should do so only after discussion with the Editor. 